\title{
Updates on USP Activities Related to Dissolution, Disintegration, and Drug Release
}

\author{
Margareth R. C. Marques and William Brown \\ U. S. Pharmacopeia, Rockville, MD, USA
}

A II revisions and updates to any USP monographs or general chapters are published in Pharmacopeial Forum (PF) for a 90-day period for public comments. Pharmacopeial Forum is available free of charge at www. usppf.com. The revisions are uploaded to the site every two months. This site allows searching by keyword and by monograph and general chapter titles. Pharmacopeial Forum has been available online since Volume 28 (JanFeb 2002).

\section{SEMISOLID DRUG PRODUCT PERFORMANCE TESTS}

The new USP General Chapter $<1724>$ Semisolid Drug Products-Performance Tests will be official in the First Supplement to USP 36 on August 1, 2013. This chapter covers the equipment (vertical diffusion cell, immersion cell, and cell for USP Apparatus 4) and the procedures that can be used to evaluate drug release from semisolid drug products such as creams, ointments, gels, and lotions. Currently, this test is not used routinely for batch release but is an important tool during product development and for post-approval changes (see FDA Guidance for Industry: Nonsterile Semisolid Dosage Forms-Scale-Up and Postapproval Changes: Chemistry, Manufacturing, and Controls; In Vitro Release Testing and In Vivo Bioequivalence Documentation). Please contact Margareth Marques (MRM@usp.org) for more information.

\section{DEVELOPMENT AND VALIDATION OF DISSOLUTION TESTS}

The USP General Chapter $<1092>$ The Dissolution Procedure: Development and Validation is under revision, and the proposed changes will be available January 2014 in Pharmacopeial Forum 40(1). A Stimuli to the Revision Process article in the same $P F$ volume will explain the changes. Please contact Will Brown (WEB@usp.org) for more information.

\section{DRUG RELEASE <724>}

When the USP General Chapter $<711>$ Dissolution was harmonized with the European Pharmacopoeia (EP) and the Japanese Pharmacopoeia (JP), parts of the USP General Chapter $<724>$ Drug Release were transferred to $<711>$ Dissolution, but the Chapter $<724>$ was not harmonized with $E P$ and $J P$.

This chapter has been completely rewritten to be more user-friendly. The drawings of some of the equipment de- scribed in the chapter were updated to better reflect what is commercially available. In addition, new accessories were added to the text. The new version of the chapter will be published in PF 39(4) [July-Aug 2013] for public comments. All comments and suggestions should be sent to Margareth Marques (MRM@usp.org) no later than Sept. 30, 2013.

\section{DISSOLUTION TESTING OF CAPSULES}

The new USP General Chapter <1094> Liquid-filled Capsules-Dissolution Testing and Quality Attributes was published in PF 38(1). After this publication, comments were received saying that most of the content of the chapter is applicable to all types of capsules. As a consequence of these comments, the chapter was completely revised to include discussion of all types of capsules (hard or soft, gelatin or starch or cellulose derivatives) and all types of capsule fill (liquid, semisolid, or solid). This chapter contains information on the influence of capsule shell composition, capsule fill formulation, storage conditions, and so forth, on the dissolution behavior of capsules. Also, it contains information on the dissolution testing conditions to be used with capsules with particular emphasis on the use of enzymes for capsules with gelatin crosslinking. The revised version of the chapter was published in PF 39(3) [May-June 2013] and will be official in the First Supplement of USP 37. Please contact Margareth Marques (MRM@usp.org) for more information.

\section{DISSOLUTION <711>}

The USP General Chapter $<711>$ Dissolution contains a paragraph allowing the use of enzymes when gelatin capsules and gelatin-coated tablets do not conform to the dissolution specification. The chapter recommends the use of pepsin for dissolution media with a $\mathrm{pH}$ of less than 6.8 and of pancreatin for media with a pH of 6.8 or greater. The text in the chapter presents some challenges. (1) It does not relate the dissolution failure with the presence of cross-linking in the gelatin. The user can assume that the enzymes can be used for any type of failure, even those not related to gelatin cross-linking. (2) Pepsin has an acceptable activity only up to a $\mathrm{pH}$ around 4 and pancreatin with a pH above 6.8. There is no enzyme recommended for the gap in this $\mathrm{pH}$ range. Also, the chapter does not give any guidance for dissolution media containing surfactants. Pepsin and pancreatin are not compatible 
with some types of surfactants. To address these issues, USP created an expert panel that is evaluating possible alternatives and modifications in the two-tier dissolution testing of cross-linked gelatin capsules. A revision to the USP General Chapter <711> Dissolution, together with the rationale for the modifications, will be published in a future issue of PF. Please contact Margareth Marques (MRM@usp.org) for more information.

\section{OPHTHALMIC PRODUCTS}

In the current version of USP there are only two chapters for ophthalmic products, $<751>$ Metal Particles in Ophthalmic Ointments and $<771>$ Ophthalmic Ointments. These chapters are out of date and address only ophthalmic ointments. Chapter $<771>$ is being revised to include a discussion of all dosage forms that can be applied to the eye. The revised chapter will incorporate the quality tests appropriate for ophthalmic products and is entitled $<771>$ Ophthalmic Products-Quality Tests. The text of the General Chapter $<751>$ Metal Particles in Ophthalmic Ointments has been transferred to $<771>$ under Particulate and Foreign Matter, and its content has been updated. Therefore, that chapter is being deleted. Consequently, all monographs for ophthalmic ointments are also being revised with the deletion of the reference to Chapter $<751>$ and to other chapters included in the new version of $\langle 771\rangle$. In place of the deleted references, a new reference, "Other requirements-meets the requirements under $<771>$ Ophthalmic Preparations-Quality Tests," will be added.

A new General Chapter <1771> Ophthalmic Preparations-Performance Tests discussing dissolution and drug release testing for ophthalmic products has been developed. The new chapter discusses some options for apparatus and conditions that could be used.

Both chapters and a Stimuli article with more information on ophthalmic dosage forms will be published in PF
39(5) [Sept. - Oct 2013]. The deadline to send comments to MRM@usp.org is Nov 30, 2013.

\section{WORKSHOP OPHTHALMIC PRODUCTS}

A workshop to discuss the new USP general chapters and other topics related to ophthalmic products including dissolution and drug release will be held at the USP headquarters in Rockville, MD, USA on Oct 21-22, 2013. The program and instructions for registration are available at http://www.usp.org/meetings-courses/workshops/ophthalmic-preparations. Please contact Margareth Marques (MRM@usp.org) for more information.

\section{TABLET SPLITTING}

A new General Chapter, <705> Quality Attributes of Tablets Labeled as Having a Functional Score, has been developed. The new general chapter gives specifications for tablets with labeling approved by the FDA under the Guidance for Industry, Tablet Scoring: Nomenclature, Labeling, and Data for Evaluation. Dissolution testing of split tablets from immediate-release and extendedrelease products is included as part of the new general chapter.

The new chapter and a Stimuli article explaining the proposed requirements will be published in PF 39(4) [JulyAug 2013]. The deadline to send comments to Will Brown (WEB@uspo.org) is September 30, 2013.

\section{WORKSHOP DISSOLUTION TESTING OF CAPSULES}

A workshop to discuss all the aspects of the dissolution testing of any types of capsules, including dietary supplements, will be held at the USP headquarters in Rockville, MD, USA on March 24-25, 2014. The preliminary program is available at http://www.usp.org/meetings-courses/ workshops . Please contact Margareth Marques (MRM@ usp.org) for more information. 